\title{
Educação Ambiental em unidades de conservação em Alegre-ES
}

\section{Environmental Education in protected areas in Alegre-ES}

\author{
Naiara Machado Neve ${ }^{1}$ \\ Anderson Lopes Peçanha ${ }^{2}$ \\ Andréia Weiss ${ }^{3}$ \\ Diego Rodrigues ${ }^{4}$ \\ Lucas Mendes Barreto ${ }^{5}$
}

\section{RESUMO}

Para que futuramente o homem esteja em consonância com o meio ambiente, há necessidade de diversas mudanças na sociedade, visando à conservação da biodiversidade e melhoria da qualidade de vida. Dessa forma a necessidade da preservação do meio ambiente e a diversidade dos seres vivos são uma preocupação mundial. Uma alternativa para chegar a isso, são as atividades não formais no ensino de educação ambiental, instrumentos de grande importância, pois possibilitam que os indivíduos modifiquem valores e comportamentos enquanto as questões ambientais. A partir disso, o objetivo deste trabalho foi avaliar a percepção ambiental de duas turmas do $1^{\circ}$ ano do ensino médio que participaram da realização de atividades não formais em duas unidades de conservação do município de Alegre-ES, região do Caparaó do Estado do Espírito Santo construindo mapas mentais sobre os locais. Após a análise dos mapas mentais os alunos compreenderam a importância da conservação da biodiversidade e do meio ambiente, perceberam também os impactos causados nas diferentes Unidades de Conservação de Alegre-ES, maior impacto foi observado na ARIE Laerth Paiva Gama em relação ao PECF Cachoeira da Fumaça. Assim, foi possível concluir que é necessária a realização de trabalhos de educação ambiental com os moradores do entorno da ARIE para minimizar os problemas ambientais ali encontrados. Assim as atividades propostas neste estudo, possibilitaram melhor percepção ambiental dos alunos participantes das atividades propostas, ressaltando assim a eficiência das atividades de educação ambiental em ambientes não formais.

Palavras-chave: Mapas mentais; percepção ambiental; biodiversidade; espaços não formais de ensino.

\section{ABSTRACT}

For future man should be in harmony with the environment, there is need for several changes in society, aimed at conserving biodiversity and improving the quality of life. Thus the need to preserve the environment and the diversity of living things are a worldwide con- cern. An alternative to get to that, are unstructured in environmental education teaching, very important tools, as they allow individuals to modify values and behavior as environmental issues. From this, the aim of this study was to evaluate the environmental perception of two classes of the 1st year of high school who participated in the realization of unstructured in two protected areas of Alegre-ES district, the Caparaó State region the Holy Spirit building mental maps

1 Universidade Federal do Espírito Santo, Centro de Ciências Agrárias, Alto universitário S/Nº 29500-000 Alegre-ES. naiara_mneves@hotmail.com

2 Universidade Federal do Espírito Santo, Centro de Ciências Agrárias, Alto universitário S/N - 29500-000 Alegre-ES. andreiaweiss@yahoo.com.br

3 Universidade Federal do Espírito Santo, Centro de Ciências Agrárias, Alto universitário S/N - 29500-000 Alegre-ES. lopes.pecanha@gmail.com

4 Universidade Federal do Espírito Santo, Centro de Ciências Agrárias, Alto universitário S/N - 29500-000 Alegre-ES. diegorlembrance@outloock.com

5 Universidade Federal do Espírito Santo, Centro de Ciências Agrárias, Alto universitário S/N - 29500-000 Alegre-ES. barreto.0305@hotmail.com 
of the locations. After analyzing the mental maps the students understood the importance of biodiversity conservation and the environment, also realized the impacts in different Alegre-ES Conservation Units, the greatest impact was observed in the ARIE Laerth Paiva Gama regarding the PECF Waterfall smoke. Thus, it was concluded that it is necessary to carry out environmental education work with residents surrounding the ARIE to minimize the environmental problems found there. Thus the activities proposed in this study, possibility Taram better environmental awareness of students participating in the proposed activities, thus underscoring the effectiveness of environmental education in non-formal environments.

Keywordes: Mental maps; environmental awareness; biodiversity; non-formal spaces of education.

\section{$1 \quad 1$ INTRODUÇÃO}

A mudança no comportamento da população é primordial para que futuramente a relação entre o homem e o meio ambiente ocorra em harmonia, promovendo assim, a conservação da biodiversidade, melhoria da qualidade de vida e um desenvolvimento sustentável (CAMPANILI; PROCHNOW, 2006). Para tentar atingir tal objetivo, a educação ambiental é uma ferramenta de suma importância, com a tendência de aliar os aspectos educacionais e afetivos, leva a uma aprendizagem mais significativa e mostra a natureza do conhecimento científico como produto do raciocínio lógico e também dos valores produzidos durante a formação escolar, fomentando com tal processo, a mudança de comportamento em relação ao meio ambiente e consequentemente uma melhor percepção ambiental (SENICIATO; CAVASSAN, 2004). A percepção ambiental pode ser definida como o homem percebe aquele ambiente que está inserido, permitindo o mesmo aprender a preservá-lo e cuidá-lo (FERNANDES et al., 2003).

Dessa forma, as aulas ministradas em ambientes naturais com atividades de educação não formal têm sido indicadas como metodologia eficaz tanto por envolverem e motivarem crianças e jovens nas atividades educativas, quanto por constituírem um instrumento de superação da fragmentação do conhecimento (BIANCONI; CARUSO, 2005). Assim, tal estratégia efetiva o aprendizado em educação ambiental, onde promove mudanças de valores e posturas dos alunos em relação à natureza, já que os problemas ambientais devem estar entre os assuntos prioritários na sociedade moderna (SENICIATO; CAVASSAN, 2004).

Com isso as formas de ensino, na qual permite o aluno construir conhecimento, são classificadas na literatura como: educação formal, educação não formal e educação informal. A educação formal pode ser definida como aquela que está presente no ensino escolar institucionalizado, estruturada hierarquicamente e cronologicamente. Já na informal adquirem-se conhecimentos, por meio de experiências diárias em casa, no trabalho e no lazer (BIANCONI; CARUSO, 2005). Entretanto define-se como educação não formal como as tentativas educacionais organizadas e sistematizadas que, normalmente, se realiza fora dos quadros do sistema formal de ensino (BIANCONI; CARUSO, 2005). Espaços não formais de ensino são descritos como recursos pedagógicos complementares que tem como objetivo tornar a educação mais prazerosa e interessante, o que pode melhorar assim o processo de ensino-aprendizagem (GUIMARÃES; VASCONCELLOS, 2006).

Partindo desta percepção o presente trabalho teve como objetivos desenvolver e avaliar atividades didático-lúdicas com temas de educação ambiental em espaços não formais de ensino utilizando a estruturação de mapas mentais por alunos do $1^{\circ}$ anodo ensino médio. Para isso, se definiu como sujeitos os alunos de dois (02) primeiros anos do Ensino Médio de uma escola estadual do município de Alegre-ES. O espaço para o desenvolvimento das atividades se constitui no Parque Estadual da Cachoeira da Fumaça (PECF) e na Área de Relevante Interesse Ecológico Laerth Paiva Gama (ARIE), estes são considerados “ambientes educativos” não formais de ensino. Uma das formas de avaliar as atividades desenvolvidas e a percepção ambiental dos alunos foi a organização de mapas mentais. 
O mapa mental é uma metodologia que permite analisar a percepção ambiental construídas em atividades em espaços não formais de educação (ARCHELA et al., 2004). A representação do aprendizado saber percebido nos mapas mentais é representada de forma simples, tal como ele é, com sua forma, histórias concretas e simbólicas, cujo imaginário é reconhecido como uma forma de compreensão do lugar (ARCHELA et al., 2004).

\section{METODOLOGIA}

O presente trabalho foi realizado em duas unidades de conservação localizada no município Alegre-ES, sendo os ambientes naturais públicos Parque Estadual Cachoeira da Fumaça (PECF) e a Área de Relevante Interesse Ecológico Laerth Paiva Gama (ARIE).

Nestes locais foram desenvolvidas atividades não formais de educação ambiental, com alunos de duas turmas de $1^{\circ}$ do ensino médio (EM) da escola Estadual de Ensino Fundamental e Médio “Aristeu Aguiar” (E.E.E.F.M “Aristeu Aguiar”) localizada no centro do município de Alegre-ES. Nessas atividades foram abor- dados alguns temas importantes como biodiversidade da fauna, flora da floresta atlântica e desenvolvimento sustentável.

O desenvolvimento da ação foi conduzido em dois momentos, num primeiro momento, foram trabalhadas com os alunos do $1^{\circ}$ ano I e IV do ensino médio, em dias diferentes, as atividades didáticas Histórico do PECF, Flanelógrafo, Trilha Interpretativa, Dinâmica do Ombro e Mapa Mental no Parque Estadual Cachoeira da Fumaça. Na última atividade realizada no PECF, esses indivíduos organizaram/criaram seus mapas mentais.

As atividades didático-lúdicas trabalhadas no Parque Estadual Cachoeira da Fumaça (PECF) foram:

1. Histórico do PECF: A Unidade de Conservação (UC) foi apresentada, explicado a classificação do PECF, características gerais do bioma, os objetivos do parque e o histórico da construção do parque. Os monito- res do PECF colaboraram nesta atividade.

2. Flanelógrafo: Com objetivo de dimensionar o bioma Mata Atlântica, um quadro de flanela com imagens de organismos e componentes do ambiente PECF foram utilizados como recurso didático que auxilia a contar e visualizar a biodiversidade da fauna e flora e suas características presentes na unidade,

3. Trilha interpretativa: Durante uma caminhada de 50 minutos pelo parque, foram abordados diversos assuntos como biodiversidade da flora da mata atlântica, o que é serapilheira, mata ciliar e suas funções. A im- portância da preservação de nascentes e da água, sustentabilidade e do projeto de reflorestamento aplicado desde a fundação do parque.

4. Dinâmica do ombro: No gramado do PECF, os alunos uniram os ombros com os ombros dos colegas ao lado e começarem a movimentarem-se aleatoriamente até chegar um movimento uniforme, um equilíbrio. A partir dessa atividade os alunos perceberiam que a humanidade poderá encontrar caminhos para o desenvolvi- mento sustentável. Isto é possível quando a comunidade percebe os cenários criados na terra, e os desafios para se tornar menos nociva ao planeta, aos outros seres vivos e a si mesmos, assim podendo entrar em consonância para obter uma vida melhor.

5. Mapa mental: Para a construção do mapa mental, foi sugerido que o mesmo e estruturasse a partir da reprodução gráfica, abordando o que tinham visto, observado e perguntado, os alunos produziram em forma de desenho a percepção do meio ambiente que eles tiveram durante as atividades. 
Num segundo momento, as mesmas turmas ( $1^{\circ}$ ano EM I e IV), foram conduzidas em uma visita guiada ao ARIE Laerth Paiva Gama, também em dias diferentes. Foi realizada a apresentação da ARIE Laerth Paiva Gama, relatos históricos dos principais fatos desde a doação do espaço para a prefeitura até a inauguração da UC, a turma foi dividida em dois grupos. Enquanto um grupo foi direcionado a trilha interpretativa, o outro grupo visitava o viveiro de produção de mudas e as casas de vegetação. Em seguida, foram realizadas, com toda a turma, as dinâmicas do Equilíbrio Ecológico e o Mapa Mental.

As atividades didático-lúdicas desenvolvidas na Área de Relevante Interesse Ecológico Laerth Paiva

Gama foram:

1. Histórico da ARIE: Foram relatados os principais fatos desde a criação do ARIE até os dias atuais, além de trabalhar o conceito de área de relevante interesse ecológico, suas características e objetivos.

2. Trilha Interpretativa: Foi abordada a importância das UC e os impactos causados pela comunidade neste local.

3. Dinâmica do Equilíbrio Ecológico: Nesta dinâmica, os alunos ficam de braços dados onde cada um, em sigilo, recebe o nome de uma espécie e ao citar esse nome o aluno cai e os colegas precisam segura-lo para manter os braços dados. Essa atividade demonstra para os alunos a importância da biodiversidade no meio ambiente, importância do seu equilíbrio e as consequências da sua perturbação, sendo importante a preservação e o auxílio para a conservação da mesma.

4. Viveiro e Casa de vegetação: Nesta atividade foi apresentado o processo de produção das mudas de espécies arbóreas e arbustivas ornamentais, além de discutir a importância dos projetos de reflorestamento e a produção de mudas para manutenção dos jardins da cidade.

5. Plantando uma Árvore: Foi trabalhada a importância do reflorestamento e a turma, de forma simbólica, contribuiu para inserção de mudas ao ambiente.

6. Mapa Mental: Como atividade final, os alunos representaram em forma de desenho a percepção da ARIE Laerth Paiva Gama. Neste momento, os alunos foram convidados à reproduzir graficamente as diferenças entre as unidades de conservação, visitadas neste trabalho, Parque Estadual Cachoeira da Fumaça e Área de Relevente Interesse Ecológico Laerth Paiva Gama.

\section{RESULTADOS E DISCUSSÃO}

O trabalho realizado foi possível observar grande entusiasmo e participação efetiva dos estudantes. Ambas as visitas, na ARIE Laerth Paiva Gama e PECF os alunos se mostraram interessados e atenciosos nas atividades desenvolvidas.

As aulas de campo têm sido consideradas uma tendência com objetivo de aliar os aspectos educacionais e afetivos, e proporcionar para o aluno aprendizagem mais significativa nas relações do homem com a natureza e no próprio ensino de biologia (SENICIATO; CAVASSAN, 2004). O fato dos alunos saírem do âmbito da escola e complementar as aulas expositivas com as saídas de campo, motivam e despertam mais interesse nos mesmos, visto que esses deixam de serem meros ouvintes e passam a participar ativamente do seu próprio processo de ensino aprendizagem (MOREIRA, 1999). 
Fukahori (2004) explica que aplicação de atividades de educação ambiental em Unidades de Conservação (UC) permite que os alunos tenham uma maior compreensão sobre aquele ambiente natural e seus impactos, pois esse contato direto promove bases que ajudam na solução de problemas ambientais. Outros autores, como Jacon e Duda (2009), afirmam também que a EA tem grande importância na mudança de comportamento, pois essa ferramenta é capaz de propiciar novos conhecimentos, na qual possibilita aos estudantes sabedoria para amenizar os problemas socioambientais, ou seja, a EA possibilita aos estudantes uma melhor percepção ambiental.

\section{1 Análise dos mapas mentais}

Na realização do mapa mental foi possível visualizar como os alunos perceberam o espaço visitado. Os mapas mentais produzidos no PECF apresentaram percepções bem semelhantes entre as turmas participantes. A turma do $1^{\circ}$ I possuía um total de 32 alunos, no entanto, a turma do $1^{\circ}$ IV possuía 27 alunos, totalizando 59 mapas mentais avaliados em cada visita. A avaliação dos aspectos dos mapas mentais, produzido pelos estudantes, foi a partir da análise individualmente dos mesmos, e associados com as argumentações dos alunos durante as visitas, visto que, durante a realização das atividades nos ambientes naturais, os alunos sempre estavam expondo seu ponto de vista.

\section{2 Mapas mentais PECF}

Durante o estudo no PECF foi estabelecido para os alunos que demonstrasse no mapa mental qual foi sua percepção ao término das atividades desenvolvidas, conforme apresentado na Tabela 1.

Tabela 1 - Pontos mais levantados durante o mapa mental pelas turmas articipantes no PECF, junho de 2013, Alegre ES.

\begin{tabular}{cc}
\hline \multicolumn{2}{c}{ Pontos levantados pelas turmas participantes } \\
\hline $1^{\circ}$ ano EM I & $1^{\text {o }}$ ano EM IV \\
\hline Desmatamento & Desmatamento \\
\hline Consciência ambiental & Consciência ambiental \\
\hline Preservação & Preservação \\
\hline Sustentabilidade & Sustentabilidade \\
\hline Extinção da fauna e flora & Extinção da fauna e flora \\
\hline Importância do comportamento & Importância do comportamento \\
\hline Biodiversidade & Projeto de reflorestamento \\
\hline Projeto de reflorestamento & Mata ciliar \\
\hline Mata ciliar & Serapilheira \\
\hline
\end{tabular}

Fonte: Neves, 2013.

Na avaliação dos mapas mentais aplicados no PECF, foram analisados os pontos percebidos pelos alunos nos desenhos, foram representados nos mapas mentais os danos causados pelo desmatamento, as consequências da degradação do meio ambiente, a importância da preservação, a importância da sustentabilidade, extinção de animais, a importância de comportamento, a biodiversidade da fauna e flora da mata atlântica, os projetos de reflorestamento e a importância e função da serapilheira e mata ciliar. Esses pontos percebidos nos mapas mentais foram os assuntos abordados no decorrer das atividades realizadas no PECF (Figura 1). 
Nesses mapas mentais, os alunos representaram os impactos que o homem causa ao meio ambiente (Figura 1A), a importância da mata ciliar e o projeto de reflorestamento para recuperar a fauna do bioma mata atlântica (Figura 1B e 1D), as ações de sustentabilidade na trilha do PECF, como exemplo a reciclagem de pneus para construção de bancos, podendo afirmar que os alunos conseguiram retratar os assuntos trabalhados nas atividades. Guerreiro (2005) afirma que é de suma relevância a construção da percepção ambiental, pois assim é possível minimizar os impactos ambientais e melhorar a qualidade de vida.

Figura 1 - Mapas mentais, dos alunos do $1^{\circ}$ ano EM I,produzidos durante as atividades no PECF.

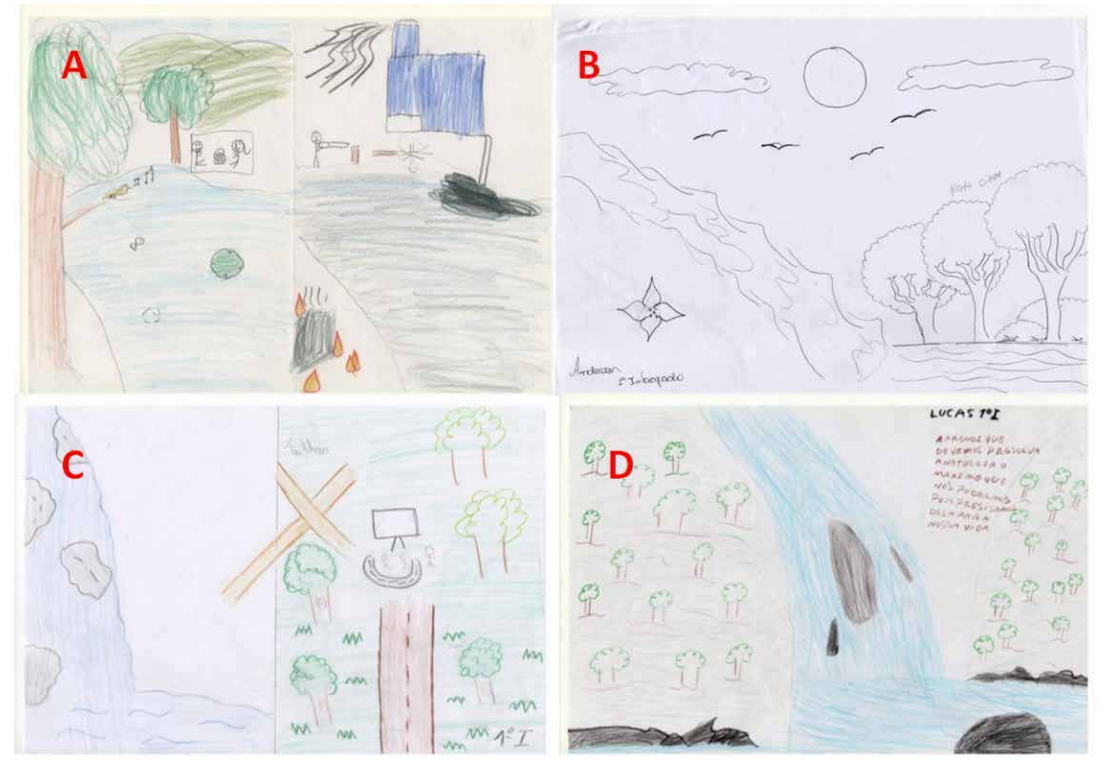

A) Diferenças dos ambientes estudados. B) Representação da mata ciliar e da cachoeira da fumaça. C) Representação do PECF. D) Representação do projeto de reflorestamento e mata ciliar. Fonte: Neves, 2013.

Já os estudantes da turma do $1^{\circ}$ ano IV, nessa atividade dos mapas mentais representaram a biodiversidade da mata Atlântica (Figura 2 A e Figura 2 D), a importância de projetos de reflorestamento, da consciência ambiental e mata ciliar para preservar o meio ambiente e assim alcançar melhor qualidade de vida (Figura $2 \mathrm{~B}$ e Figura 2C). Dessa forma, os mapas mentais produzidos podem ser considerados um instrumento para avaliar como os alunos estão percebendo o ambiente estudado (FISCHER, 2005). Na visita ao PECF pôde-se perceber que ambas as turmas enxergaram a importância das questões ambientais para a sociedade. Outros estudos, com de Souza (1998), certifica a importância de atividades, em ambientes naturais, que possibilite a construção de uma melhor percepção ambiental. 
Figura 2 - Mapas mentais dos alunos do $1^{\circ}$ ano IV das atividades desenvolvidas no PECF.
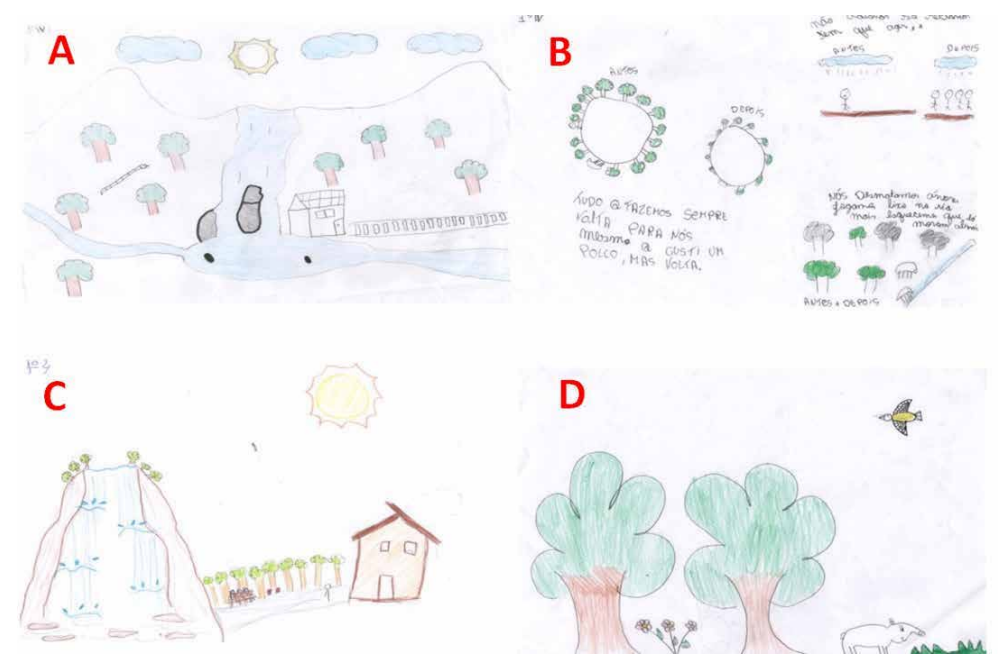

A) Representação da biodiversidade da mata atlântica. B) Representação da importância da consciência ambiental e a preservação do meio ambiente. C) Representação do PECF. D) Representação da biodiversidade da Mata Atlântica. Fonte: Neves, 2013.

A percepção ambiental da turma $1^{\circ}$ ano EM IV, por meio dos mapas mentais, foi representada por tema como preservação, biodiversidade, o projeto de reflorestamento e mata ciliar, como destacado na figura 3.

Figura 3 - Temas abordados nos mapas mentais pelos alunos do $1^{\circ}$ ano EM IV da EEEFM Aristeu Aguiar durante a visita ao PECF, Alegre, junho de 2013.

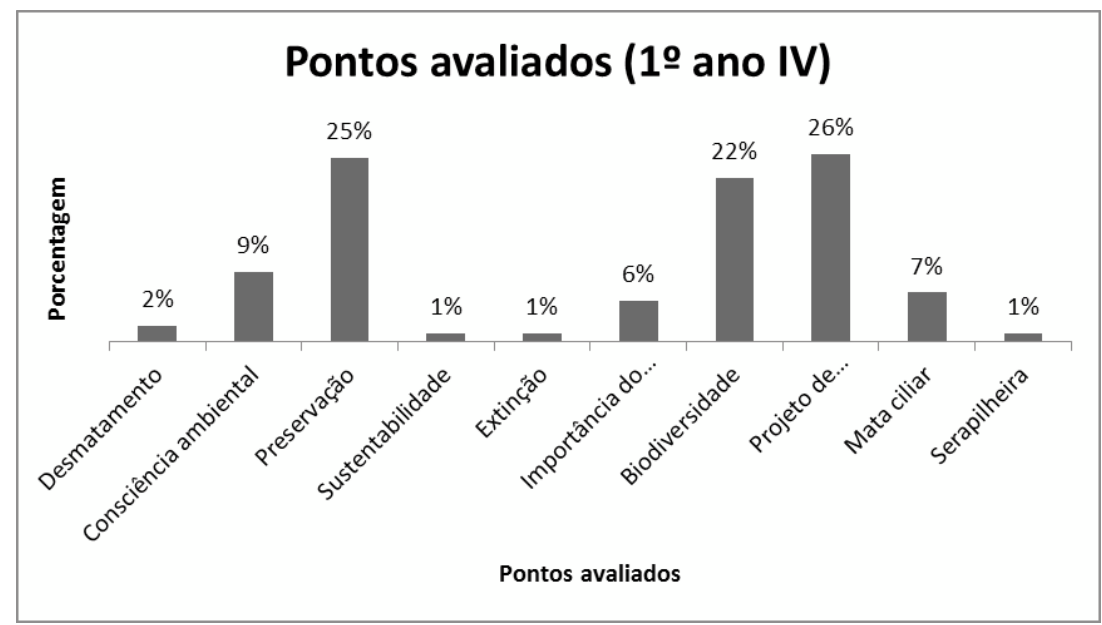

Fonte: Neves, 2013.

Na visita do PECF com a turma do $1^{\circ}$ ano EM IV, os pontos mais representados (preservação, biodiversidade, projeto de reflorestamento e consciência ambiental) são justificados, pois esses alunos mesmo com perfil mais acanhado nessa aula de campo tiveram uma participação aguçada durante a trilha interpretativa, onde foram abordados esses assuntos. Ao finalizar a trilha foram realizadas perguntas a fim de revisar os temas abordados, mais de $70 \%$ dos alunos souberam responder. Algumas das perguntas realizadas foram: "Qual bioma do nosso estado?”; “O que é mata ciliar?” “O que é e serapilheira?” “Qual a importância das nascentes?”. 
O ponto biodiversidade foi bastante representado nos mapas mentais, isto pode ser atribuído à dinâmica do flanelógrafo, que em forma de história foram abordados os animais e os vegetais presentes na mata atlântica, os alunos nessa metodologia demonstraram interesse e atenção.

Contra partida a visita ao PECF com os alunos da turma $1^{\circ}$ ano I, na metodologia dos mapas mentais, apresentaram os pontos da seguinte forma (Figura 4). Para o $1^{\circ}$ ano EM I, os pontos representados (projeto de reflorestamento, consciência ambiental, sustentabilidade e preservação) são justificados pela trilha interpretativa realizada, na qual a turma teve grande participação.

\section{Figura 4 - Temas abordados nos mapas mentais pelos alunos do $1^{\circ}$ ano EM I da EEEFM Aristeu Aguiar durante a visita ao PECF, Alegre, junho de 2013.}

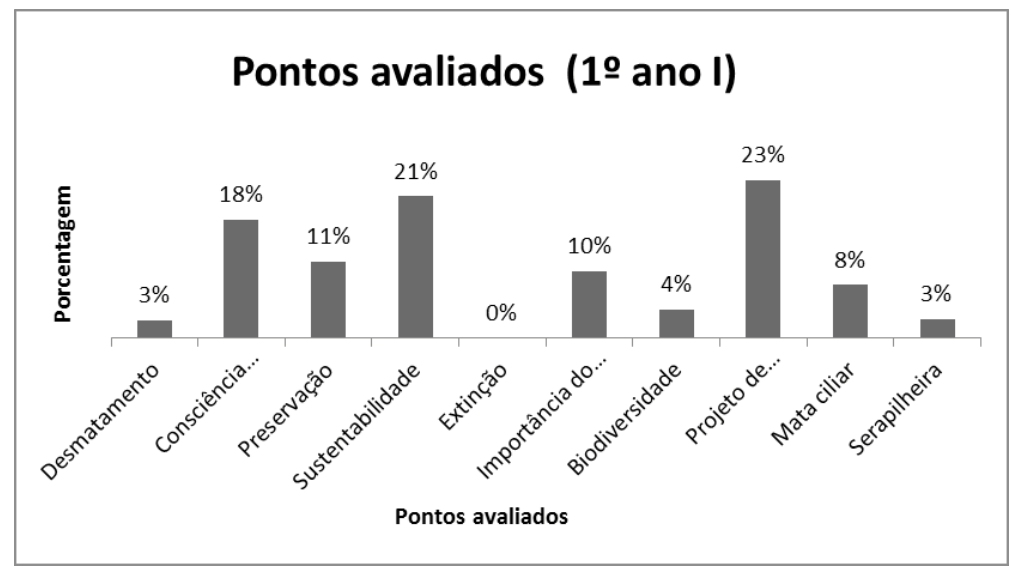

Fonte: Neves, 2013.

O fato de a sustentabilidade ser representada deve-se a parada realizada no espaço denominado "espaço verde” (PECF) para contemplar a natureza e a beleza da cachoeira, os acentos desse espaço são feitos de pneus velhos e com presença de árvores e vegetação nativa. Nesse momento foi discutida a importância da sustentabilidade no nosso dia-dia e os benefícios das ações sustentáveis para o meio ambiente. A professora da classe contribuiu com a abordagem desse assunto, dando exemplos práticos que podem ser realizados por cada um. O “espaço verde” é um local da trilha arborizado, justificando assim seu nome, com maior altitude que foi construída para comtemplar a cachoeira e abordar, durante a trilha, o assunto sustentabilidade (Figura 5).

Figura 5 - Alunos da escola EEEFM Aristeu Aguiar durante a visita ao PECF, Alegre, junho de 2013.

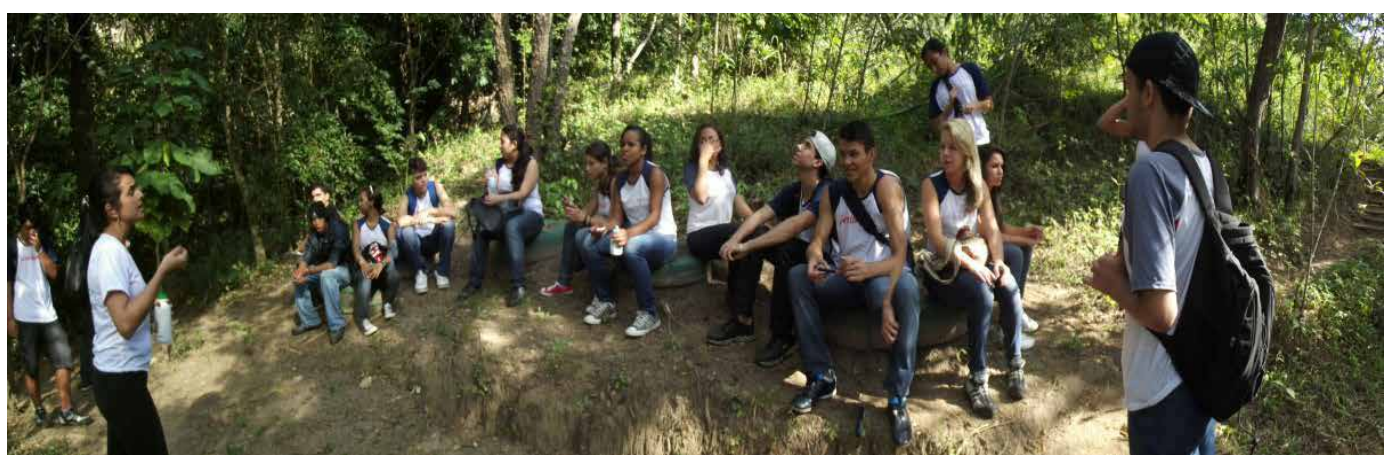

Fonte: Neves, 2013. 
Os mapas mentais utilizados no presente trabalho inferiram na percepção ambiental dos alunos nas duas visitas realizadas, pois retrataram graficamente vários aspectos que os alunos perceberam nas realidades vivenciadas. Dessa forma, pode-se afirmar que os alunos analisaram satisfatoriamente as atividades trabalhadas nos ambos ambientes. Oliveira (2006) diz que os mapas mentais exercem a função de tornar os sentimentos, pensamentos e atos mais visíveis da realidade percebida. O mesmo autor afirma também que os mapas mentais não devem ser considerados apenas desenhos, mas sim avaliados com critérios, pois contém representações da mente humana que muitas vezes não são expressas em palavras e ações.

Outros autores, como Souza (1998) e Fischer (1994), afirmam que os mapas mentais representam a cognição humana dos espaços vivenciados, e que os mesmos servem de ferramenta para compreender e avaliar o comportamento do indivíduo no meio. Assim os mapas mentais representam a interação do homem com o meio que está inserido, permitindo assim, tomar medidas de gerenciamento que minimize os impactos presentes (GUERREIRO et al., 2005).

\section{3 Mapas mentais da ARIE Laerth Paiva Gama}

Na visita a ARIE Laerth Paiva Gama foi solicitado também, no fim das atividades, que os alunos organizassem o mapa mental com as percepções que os alunos tiveram daquele ambiente e, além disso, também se solicitou que representassem as principais diferenças percebidas nas duas UC em que foram realizadas as atividades propostas. Dessa forma, a Tabela 2 apresenta as diferenças apontadas nestas.

Tabela 2 - Pontos levantados durante o mapa mental pelas turmas participantes na ARIE Laerth Paiva Gama, junho de 2013, Alegre ES.

Pontos levantados pelas turmas participantes

\begin{tabular}{|c|c|}
\hline $1^{\circ}$ ano I & $1^{\circ}$ ano IV \\
\hline Organização & Organização \\
\hline Presença de lixo no ARIE Laerth Paiva Gama & Presença de lixo no ARIE Laerth Paiva Gama \\
\hline Preservação mais efetiva no PECF & Responsabilidade da comunidade mais efetiva no PECF \\
\hline Atos sustentáveis mais presente no PECF & $\begin{array}{c}\text { Presença de casas popular muito próximo } \\
\text { ao ARIE Laerth Paiva Gama }\end{array}$ \\
\hline Responsabilidade da comunidade mais efetiva no PECF & Projeto de reflorestamento mais presente no PECF \\
\hline \multicolumn{2}{|l|}{ Presença de casas popular muito próximo } \\
\hline \multicolumn{2}{|l|}{ Desmatamento mais presente na ARIE Laerth Paiva Gama } \\
\hline Projeto de reflorestamento mais presente no PECF & \\
\hline
\end{tabular}

Fonte:Neves, 2013.

A maioria dos alunos citou como diferença entre as unidades de conservação os aspecto de organização, quantidade de lixo, reflorestamento e a responsabilidade da comunidade do entorno com a própria UC. A ARIE Laerth Paiva Gama comparada com o PECF deixa a desejar nos aspectos da organização física da UC, na quantidade de lixo encontrado na área da unidade, na falta de responsabilidade da população que mora no entorno, entretanto, o PECF possui projetos de reflorestamento muito mais efetivo do que na ARIE Laerth Paiva Gama, como pode ser analisado na Figura 6. 
Figura 6 - Mapas mentais dos alunos do $1^{\circ}$ ano I das atividades
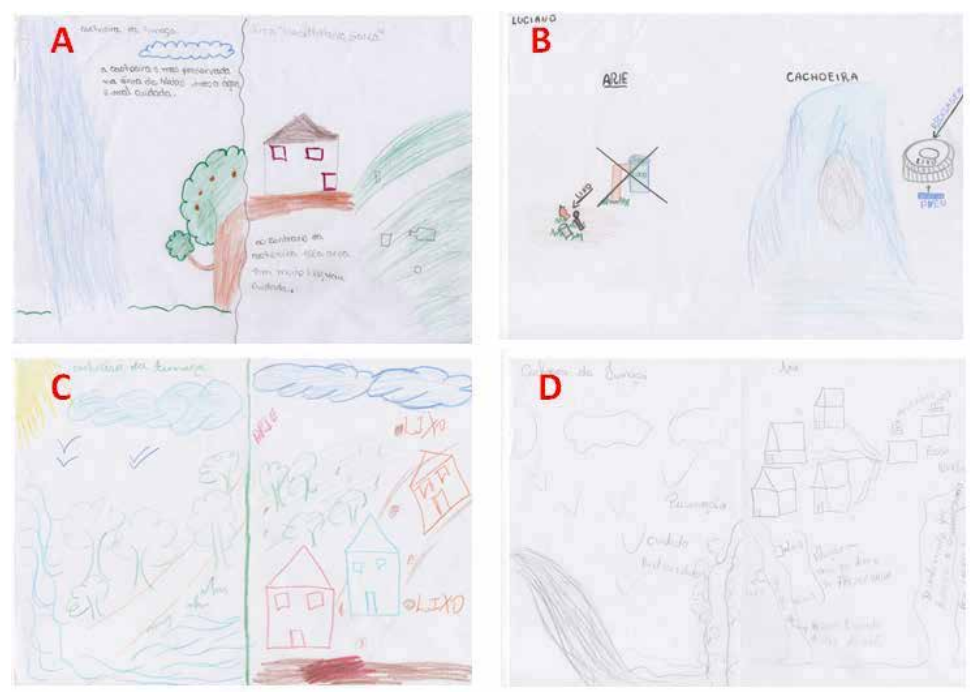

A) Representação da diferença da organização entre as unidades de conservação. B) Representação de atividades de sustentabilidade no PECF e presença de lixo na ARIE Laerth Paiva gama. C) Representação da presença de casas e lixo na ARIE Laerth Paiva Gama e a presença de mata, em torno da trilha, no PECF. D) Representação da presença de lixo e casas populares na ARIE Laerth Paiva Gama e as dificuldades ali encontradas. Fonte: Neves, 2013.

Os alunos do $1^{\circ}$ ano IV representaram nos mapas mentais a quantidade de lixo jogado na ARIE Laerth Paiva Gama, presença de casa popular muito próximo da UC, a trilha construída pelos moradores, localizada dentro da UC, para obter melhor acesso. Representaram também a presença de esgoto sem tratamento das casas ali encontradas e um dado que chamou a atenção, principalmente dos alunos foi a presença de vestígios de uso de drogas e a presença de prostituição na própria UC (ALEGRE, 2005).

A Figura 7 e 8 são apresentadas as diferenças entre as UC observadas pela turma do $1^{\circ}$ ano EM IV e $1^{\circ}$ ano EM I, respectivamente.

Figura 7 - Diferenças observadas entre as UC pelos alunos $1^{\circ} \mathrm{EM}$ IV

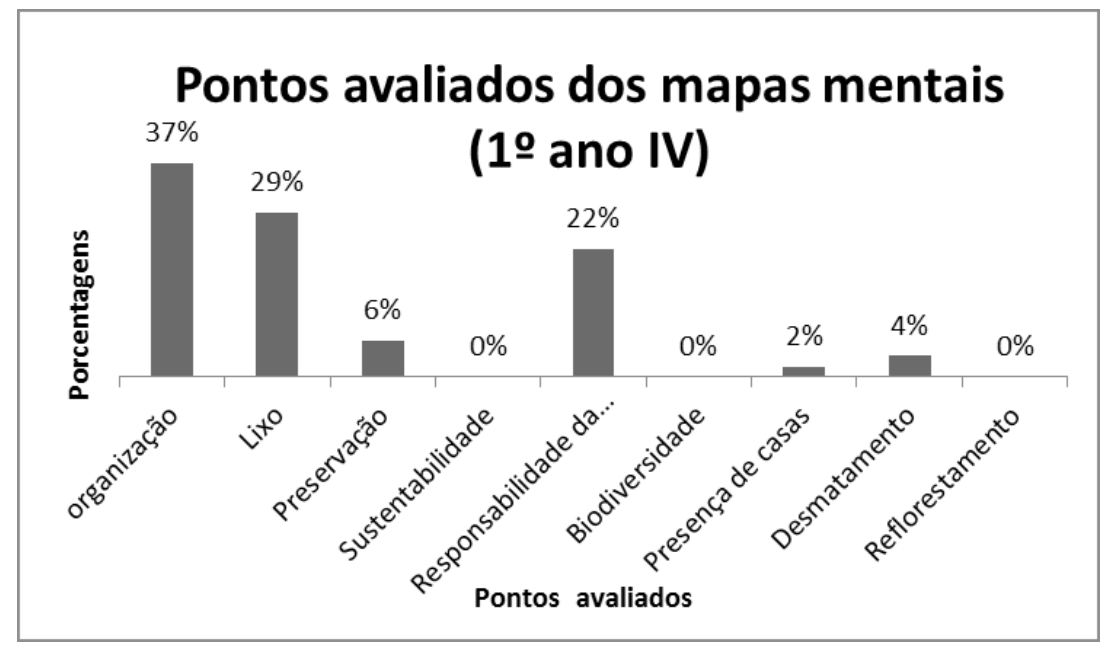

Fonte: Neves, 2013 
Figura 8 - Diferenças observadas entre as UC pelos alunos $1^{\circ} \mathrm{EM} \mathrm{IV}$

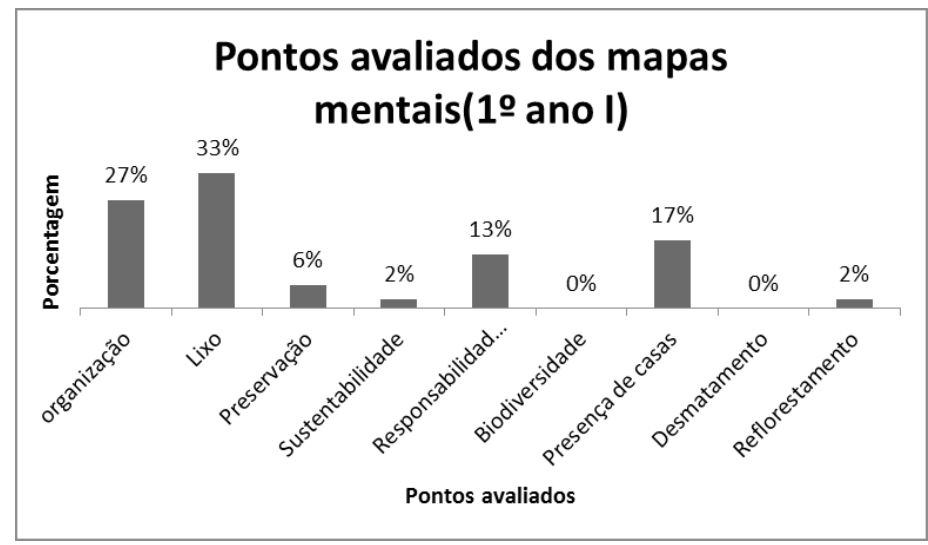

Fonte: Neves, 2013.

Dessa forma, na visita a ARIE Laerth Paiva Gama as duas turmas ( $1^{\circ}$ ano EM I e IV) os pontos mais representados foram a diferença entre a organização das UC, quantidade de lixo e responsabilidade da comunidade. A presença de lixo na ARIE foi muito mais presente que no PECF. Esse lixo encontrado nessa área está diretamente ligado com a falta de responsabilidade da comunidade, que contribui para a degradação de um local que deveria ser preservado. Fernandes et al., (2003) afirmam que com o estudo da comunidade pode-se entender melhor a relação do meio ambiente em que se está inserido, o que pode assim solucionar os problemas ali encontrados, assim a EA aliada com esse estudo possibilita a informação das pessoas para a solução das problemáticas que nos cercam. Mudar a percepção ambiental das pessoas a partir da EA é de suma importância para alcançar resultados mais positivos no processo de preservação dos recursos naturais (TORRES; OLIVEIRA, 2005). Os mesmos autores afirmam que a partir da EA é possível atender melhor as deficiências encontradas em cada comunidade.

Com o desenvolvimento das atividades os alunos puderam presenciar a grande presença de lixo na ARIE, outro fato percebido, foram os moradores da comunidade passando pela trilha através do horto e jogando lixo no caminho dentro da ARIE, visto que esses fatos confirmam a falta de organização da gestão da ARIE Laerth Paiva Gama. Outro ponto que foi levantado pelos alunos da turma $1^{\circ}$ ano EM I foi a presença de casas populares pró- ximo à ARIE. Ao realizar a trilha, a turma chegou próximas as casas, onde foi possível evidenciar os problemas sanitários e o os riscos de contaminação ali presentes, fundamentando a representações dessas casas nos mapas mentais produzidos por essa turma (Figura 9).

Figura 9 - Mapa mental representando casas populares próximo à ARIE.

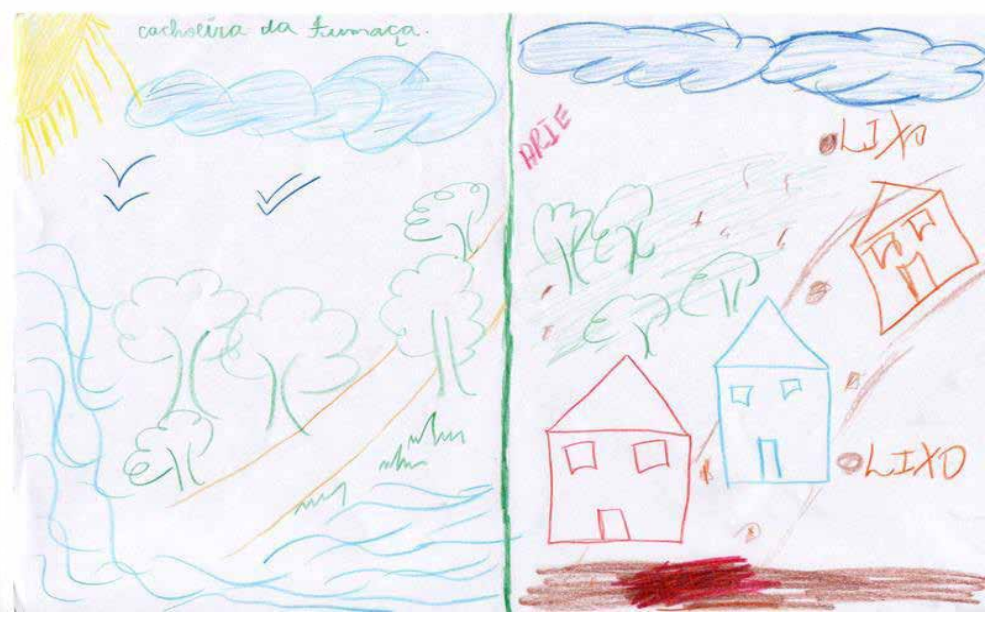

Fonte: Neves, 2013 
Entretanto, no PECF esse aspecto da consciência ambiental da comunidade do entorno é bem trabalhada com a população daquele local, pois pode ser percebido pela organização e limpeza daquela UC. A população da área e os turistas que visitam o PECF são muito bem informados das regras da UC ao chegarem à área, ou seja, há um trabalho de EA nesse ambiente. Outra justificativa para ausência de lixo no PECF é o fato da comunidade ser bem exigentes e preocupados com as regras da UC e o PECF está localizado longe dos centros urbanos, ao contrário da ARIE Laerth Paiva Gama, em que a comunidade é bem carente e muito próxima do centro urbano, o que pode dificultar amenização dos impactos causados na ARIE Laerth Paiva Gama.Assim a EA justifica as percepções ambientais diferentes presenciadas entre as comunidades do PECF e ARIE. De acordo com Palma (2005), é por meio da união da percepção ambiental e EA que é possível analisarem as fontes de satisfação e insatisfação dos indivíduos que serão trabalhados, para assim almejar os objetivos propostos.

Assim, ambas as turmas que participaram da visita da ARIE Laerth Paiva Gama obtiveram a percepções semelhantes ao realizarem as atividades, esse fato é justificado pelo fato de todas as atividades serem realizadas da mesma forma com as diferentes turmas. Assim, acredita-se que a padronização das atividades, ao serem desenvolvidas com as turmas participantes ( $1^{\circ}$ ano I e o $1^{\circ}$ ano IV) nas visitas, é a razão de ambos os estudantes terem a percepções muito semelhantes, o que contribuiu para os resultados ( Figura 10).

\section{Figura 10 - Mapas mentais dos alunos do $1^{\circ}$ ano IV das atividades desenvolvidas na ARIE Laerth Paiva Gama.}
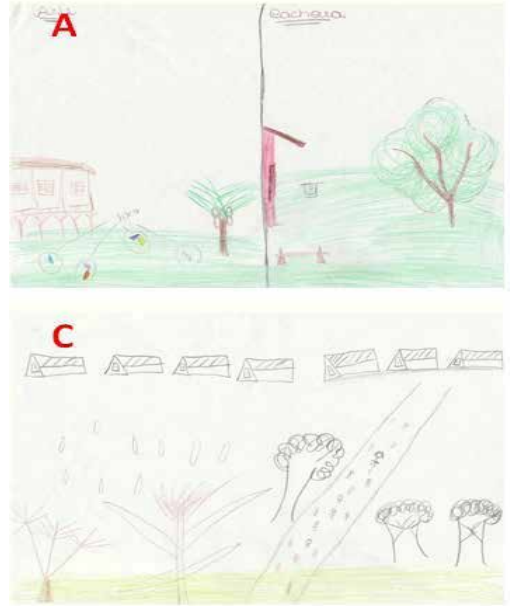

B

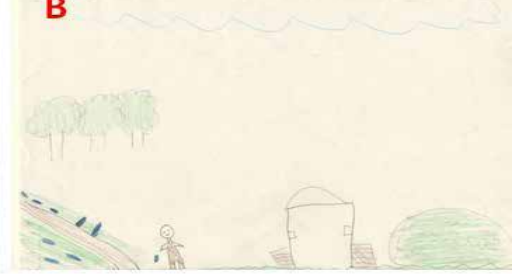

D

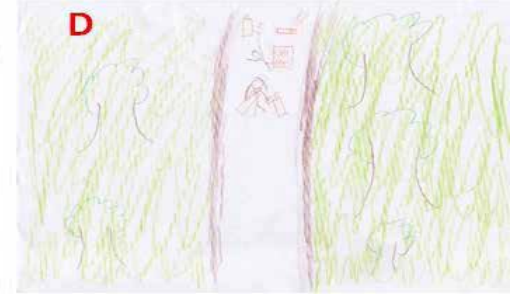

Fonte: Neves 2013.

A) Mapa mental representando a diferença entre ARIE e PECF. B) Mapa mental representando a presença de lixo na ARIE. C) Mapa mental representando a presença muito próxima da ARIE. D) Presença de trilha construída pelos moradores para o tráfico e prostituição na ARIE.

\section{CONSIDERAÇÕES FINAIS}

No presente estudo foi verificada a relevância das atividades de educação ambiental desenvolvidas nas Unidades de Conservação Parque Estadual Cachoeira da Fumaça (PECH) e Área de Relevante Interesse Ecológico (ARIE) Laerth Paiva Gama. As atividades estimularam a participação dos alunos no seu próprio processo de aprendizado. Comprovando assim, que aulas em ambientes naturais permitem que os alunos participem ativamente do processo de construção de conhecimento tornando as aulas mais interessantes para os alunos. Com a metodologia de mapa mental aplicada pôde-se aferir a eficiência das atividades desenvolvidas e a percepção ambiental dos alunos, que foi bem retratada pelos participantes nos desenhos produzidos, na qual perceberam a importância da conservação do meio ambiente e o equilíbrio do mesmo. As atividades desenvolvidas nas duas 
UC permitiram que os alunos pudessem perceber as diferenças entre as UC e a importância da percepção ambiental dos moradores do entorno, visto que era presente nos moradores do entorno do PECF e ausente na ARIE Laerth Paiva Gama. Vale ressaltar ainda, o papel que a Educação Ambiental assume na tentativa de promover mudanças de comportamento, na qual possibilita minimizar os problemas socioambientais e obter melhoria na qualidade de vida.

Dessa forma, pode-se concluir que é necessário um bom trabalho na comunidade em torno da ARIE, para assim amenizar as problemáticas ambientais existentes naquele local. 


\section{REFERÊNCIAS}

ALEGRE, Secretaria Municipal de Agricultura e Meio Ambiente de Alegre ES. Diagnostico sócio ambiental da ARIE Área de Relevante Interesse Ecológico “Laerth Paiva Gama”, Alegre ES, 2005.

ARCHELA, R. S.; GRATÃO, L. H. B.; TROSTDORF, M. A. S. O lugar dos mapas mentais na representação do lugar. Revista geografia (online), Londrina, v. 13, n. 1, p. 127-141, junho de 2004.

BIANCONI, M. L.; CARUSO, F. Educação não formal. Cienc. Cult., São Paulo, v. 57, n. 4, Oct./Dec. 2005. Disponível em: <http://cienciaecultura.bvs.br/scielo.php?pid=S000967252005000400013\&script=sci_arttext $>$. Acessado em: 21 mar. 13.

CAMPANILI, M.; PROCHNOW, M. (orgs.). Mata atlântica: Uma rede pela floresta. Brasília: rma, 2006.

FERNANDES, R. S. et al. Uso da percepção ambiental como instrumento de gestão em aplicações ligadas às áreas educacional, social e ambiental. Vitória, 2003. Disponível em: $\leq$ http//www.redeceas.esalq.usp.br/ Percepção_Ambiental.pdf $>$. Acesso em: 12 out. 2013.

FISCHER, G. N. Psicologia Social do Ambiente. (Coleção perspectivas ecológicas): Instituto Piaget, Lisboa. 1994.

FUKAHORI, S. T. I. Trilha da Restinga do Maciambu: concepção, implantação, interpretação ambiental e avaliação como contribuição ao processo de educação ambiental no parque estadual da serra do tabuleiro. Disponível em: <https://repositorio.ufsc.br/handle/123456789/87411>. Acesso em: 05 dez. 2013

GUERREIRO, O; MATAREZI, J.; SPERB, R.M.; BARREIROS, L. P. Definição de uma metodologia para modelagem de agentes inteligentes difusos a partir da técnica de mapas mentais: Um estudo de caso baseado na percepção e comportamento de usuários da praia Brava. Ciência \& Tecnologia, Santa Catarina, v. 5, n. 1, p. 73, 2005.

GUIMARÃES, M.; VASCONCELLOS, M. M. N. Relações entre educação ambiental e educação em ciências na complementaridade dos espaços formais e não formais educação. Educar, Curitiba, n. 27, p. 147-162, 2006.

JACON, C.; DUDA, L. Educação ambiental em unidade de conservação: uma novaperspectiva através da recreação. Monografia. (Especialista em Educação e Gestão Ambiental) - Pós-graduação, ESAP/Faculdades Integradas do Vale do Ivaí, 2009.

MOREIRA, M.A. A teoria do desenvolvimento cognitivo de Piaget. In: MOREIRA, M.A. Teorias de aprendizagem. São Paulo: EPU. 1999. p. 95-107.

OLIVEIRA, N.A. S. AEducação Ambiental e a Percepção Fenomenológica, Através De Mapas Mentais. Revista Eletrônica do Mestrado em Educação Ambiental, v. 16, p. 32-46, 2006.

PALMA, I. R. Análise da percepção ambiental como instrumento ao planejamento da educação ambiental.

2005. 72 f. Dissertação (Mestrado em Engenharia) - Escola de Engenharia, Universidade Federal do Rio Grande do Sul, Porto Alegre, 2005.

SENICIATO, T.; CAVASSAN, O. Aulas de campo em ambientes naturais e aprendizagem em ciências - um estudo com alunos do ensino fundamental. São Paulo, v. 10, n. 1, p. 133-147, 2004.

SOUZA, C. L. Cognição Ambiental e Leitura da Paisagem Urbana: Teoria e Práctica. In: OLIVEIRA, Lívia de; MACHADO, Lucy Marion Calderini Philadepho (Orgs.). $3^{\circ}$ Encontro interdisciplinar sobre o estudo da Paisagem, UNESP: Rio Claro. 1998.

TORRES, D. F.; OLIVEIRA, E. S. Percepção Ambiental: Instrumento Para Educação Ambiental em Unidades De Conservação. Revista Eletrônica do Mestrado em Educação Ambiental, v. 21, p. 227-235, 2008. 